\title{
La multiterritorialización del conflicto de las hidroeléctricas: los reasentamientos como puntos de empoderamiento del movimiento de los afectados por represas
}

\author{
Humberto José da Rocha \\ Universidade Federal da Fronteira Sul \\ humberto.rocha@uffs.edu.br
}

\begin{abstract}
Resumen
El sector eléctrico brasileño, de matriz predominantemente hídrica, produce impactos socioambientales, de entre los cuales destaca el desplazamiento forzoso de las poblaciones locales. La desterritorialización y re-territorialización provocada por las hidroeléctricas producen un proceso social de "multiterritorialización" del conflicto. Este trabajo discute este conflicto, que involucra a consorcios de empresas constructoras y al Movimiento de Afectados por Represas (MAB), como cuestionador de estas obras. El objetivo es analizar en qué medida los reasentamientos organizados por el MAB, con origen en la construcción de una central hidroeléctrica, potencian las acciones del movimiento contra las futuras construcciones. Con una mezcla de investigación cualitativa y datos cuantitativos, presentamos el caso de la cuenca del río Uruguay, para demostrar que, aunque representen puntos de empoderamiento, el potencial de los reasentamientos necesita ser relativizado desde el punto de vista de un proceso social más amplio.

Palabras clave: conflicto; hidroeléctricas; movimientos sociales; reasentamientos; territorialidad.
\end{abstract}




\section{Abstract}

\section{The multiterritorialization of the conflict with hidroelectrical plants: resettlements as empowerment points of the movement of people affected by dams}

The Brazilian electrical sector, with a predominant hydric matrix, generates social and environmental impacts, among which stands out the compulsory displacement of local populations. The de-territorialization and re-territorialization caused by hydroelectric plants produce a process characterized by "multiterritorialization" of conflict. This paper discusses this conflict, which involves consortiums of construction companies and the Movement of People Affected by Dams (MAB), as a contesting movement. The objective is to analyze to what extent resettlements produced by the construction of hydroelectric dams and organized by MAB potentiate actions against future constructions. Combining qualitative research with quantitative data, we present the case of the Uruguay basin, in order to demonstrate that, although they represent empowerment points, the potential of resettlements must be relativized from the standpoint of a broader social process.

Key words: conflict; hydroelectrical plants; social movements; resettlements; territoriality.

\section{Introducción}

La hidroelectricidad corresponde a aproximadamente $85 \%$ de la capacidad instalada de generación eléctrica en Brasil (ANEEL/BIG, 2015). Las Centrales Hidroeléctricas de Energía (Usinas, Hidroelétricas de Energia, UHE por sus siglas en portugués) involucran a grandes áreas de tierra alcanzadas por la formación de los reservorios, instalación de canteros de construcción, caminos para circulación de personal, material y líneas de transmisión de energía que, entre varios costos externos, incluyen el desplazamiento forzoso de la población local, un punto neurálgico de la discusión en términos socioambientales. En estas cuestiones, y especialmente las específicamente ambientales, las discusiones tienden a asumir escalas globales, ya que las "dimensiones de la política, de las relaciones de poder, del ejercicio de la diferencia que se realizan en la dimensión local, permanecen convenientemente subsumidos". Nuestro desafío es tratar de rescatar los "procesos locales" en el sentido de incorporarlos a nuevos marcos y categorías de análisis de los "procesos globales" (Zhouri y Oliveira, 2010: 444).

El análisis de la cuestión hidroeléctrica brasileña requiere la conciencia de que se trata de un proceso social en el que cada nueva hidroeléctrica ins- 
tituye una relación conflictiva por el espacio y en consecuencia por los recursos naturales. Los agentes sociales y los intereses diversos establecen relaciones de poder, la mayoría de las veces asimétricas, que resultan en reconfiguraciones sociales en las que podemos percibir tendencias mínimas en cuanto a la disposición de las alianzas y las rivalidades. Observamos estas tendencias agrupadas, sobre todo, bajo dos perspectivas ideológicas que van al encuentro de la idea de los "proyectos políticos", presentados por Dagnino, Olvera y Panfichi "para designar los conjuntos de creencias, intereses, concepciones de mundo, representaciones de lo que debe ser la vida en sociedad, que orientan la acción política de los diferentes sujetos" (Dagnino, Olvera y Panfichi, 2006: 199).

Si trasladamos esta distinción genérica a la cuestión hidroeléctrica, podemos identificar dos tendencias que, aun cuando no signifiquen grupos cerrados, ayudan a orientar el análisis de manera que se pueda distinguir la naturaleza de las acciones de los agentes involucrados. Por un lado, bajo una perspectiva "neoliberal", "la primacía del mercado, en tanto eje reorganizador de la economía, se ve como si debiera extenderse al conjunto de la sociedad" (Dagnino, Olvera y Panfichi, 2006: 55). En lo relativo a las hidroeléctricas, se observa esta tendencia principalmente en los consorcios formados por el Estado y por empresas de capital privado, alianzas que se han consolidado a través de las Sociedades de Propósito Específico (SPE). ${ }^{1}$ Por otro lado, vislumbramos una perspectiva "democrático-participativa" en la cual "la participación de la sociedad en los procesos de decisión asume un papel central", vista como "instrumento de la construcción de una mayor igualdad” y "ciudadanía” (Dagnino, Olvera y Panfichi, 2006: 48-52). En la cuestión de las hidroeléctricas, esta línea está representada principalmente por el Movimiento de los Afectados por las Represas (Movimento dos Atingidos por Barragens, MAB por sus siglas en portugués) en el sentido de oposición al proyecto de las hidroeléctricas.

Sin duda, la complejidad hidroeléctrica no puede resumirse en el conflicto entre dos grupos. En una tesis defendida recientemente hicimos un esfuerzo de relacionar esta multiplicidad de grupos que van desde empresas transnacionales, hasta ribereños que pocas veces en la vida se apartaron de la barranca de un río (Rocha, 2013). Asimismo, con base en este panorama general abordamos esta cuestión, especialmente el desplazamiento forzoso, bajo la luz del protagonismo conflictivo entre las SPE y el MAB. Analizamos

${ }^{1}$ Según la Ley n. 11079, del 30 de diciembre de 2004, los proyectos hidroeléctricos serán realizados por las respectivas SPE que son creadas en virtud de aquella planta que pretendan instalar y operar. 
este conflicto tomando en cuenta las modalidades de reubicación poblacional recurrentes en las principales hidroeléctricas de Brasil, ${ }^{2}$ tratando de tomar en cuenta su repercusión en las relaciones de poder. Nuestro objetivo general es comprender en qué medida estas modalidades de reubicación poblacional afectan en la secuencia del proceso social de la hidroelectricidad. Como objetivo específico, pretendemos verificar en qué medida los afectados, en especial los reasentados, participan en movilizaciones sociales posteriores a su reubicación, tratando de señalar los argumentos para dichas iniciativas. Dicho de otra manera, pretendemos analizar en qué medida los Reasentamientos Rurales Colectivos (RRC), modalidad propuesta por el MAB, representan puntos de empoderamiento del movimiento social en este conflicto contra los consorcios que proponen los proyectos de hidroeléctricas.

Para dar cuenta de este desafío, teóricamente la discusión se fundamenta en el concepto de "multiterritorializacion", según el cual analizamos los movimientos de "territorialización", "desterritorialización" y "reterritorialización" inherentes tanto a la movilización de los capitales como en lo que se refiere a la reubicación poblacional derivada de la instalación de obras de gran escala, como las hidroeléctricas (Haesbaert, 2005; Ianni, 1997; Castells, 2003). El concepto de "malla de análisis" ayuda en la comprensión de la racionalidad entre hidroeléctricas y reasentamientos en tanto "puntos de poder" a lo largo del proceso (Raffestin, 1993). Una vez localizados esos puntos, en lo que tiene que ver con la acción colectiva, la discusión se basa en las teorías de la "movilización de recursos" y "movilización política", derivadas de la perspectiva estadounidense de estudios sobre movimientos sociales (Olson, 2015; Tilly, 1997; Tarrow, 2009). En este sentido, nuestro análisis se centra tanto en el MAB como movimiento social, como en las SPE que son grupos compuestos por el Estado y la iniciativa privada.

Este andamiaje teórico dialoga con la investigación empírica que realizamos en el ámbito de un proyecto de investigación intitulado "Evaluación de los resultados y propuesta de modelo de elaboración de programas de reubicación de la población afectada por proyectos hidroeléctricos en la cuenca del río Uruguay". Se realizó trabajo de campo durante los años 2012 y 2013, en el que se involucró a 17 alumnos de licenciatura y posgrado para la realización de entrevistas cuantitativas (survey) con 632 familias reubicadas por las principales hidroeléctricas de la cuenca del Río Uruguay (Ita, Machadinho, Barra Grande, Campos Novos y Foz do Chapecó). Los datos fueron trabajados cuantitativamente a través del programa Statistical Package for the Social Sciences (SPSS) y cualitativamente a través de entrevistas a profundidad.

\footnotetext{
${ }^{2}$ Sobre las particularidades de las modalidades, véase Rocha (2012b).
} 
Una vez obtenidas las entrevistas realizadas entre las familias reubicadas por las diferentes modalidades disponibles, específicamente para este trabajo concentraremos nuestro análisis en la modalidad de Reasentamiento Rural Colectivo (RRC), porque entendemos que es la que defiende el MAB, y es en la que el movimiento social tiene su mayor participación.

Este trabajo se encuentra estructurado de forma que en esta introducción presentamos un panorama teórico, empírico y metodológico de la propuesta de conformidad con la realidad de la cuestión hidroeléctrica brasileña. En la siguiente sección presentaremos la cuenca del Uruguay, nuestro locus de investigación, bajo la perspectiva de "malla de análisis", en la cual están reunidos "puntos de poder" representados por agentes sociales identificados con tendencias distintas; es decir, las hidroeléctricas instaladas por los consorcios y los reasentamientos organizados por el MAB. En las dos secciones subsecuentes mostraremos a los principales representantes de las dos tendencias en cuestión. Primero, las SPE, sus agentes y acciones, teniendo a las hidroeléctricas como puntos de referencia. Después, el MAB, con los reasentamientos como principal referencia. La coexistencia de estas dos perspectivas conlleva el estudio de movimientos de "desterritorializacion" del conflicto, lo que haremos en la sección analítica, en la cual presentamos como resultado de la investigación la influencia de las modalidades de reubicación poblacional —en especial los reasentamientos - en el proceso social que involucra a la hidroelectricidad, para luego presentar las consideraciones finales, que sintetizan nuestros resultados y apuntan hacia posibles investigaciones futuras.

\section{La cuenca hidrográfica como una "malla" para el análisis}

Cualquier central hidroeléctrica se planea para determinado lugar de acuerdo con las características físicas del mismo. Esto remite al concepto de "aprovechamiento óptimo", que es "todo potencial definido en su concepción global por el mejor eje de la cortina de la represa con arreglo físico general, niveles de agua operativos, reservorio y potencia, integrante de la alternativa escogida para división de caídas hidráulicas de una cuenca hidrográfica" (República Federativa de Brasil, 1995). Dicho de otra manera, el "aprovechamiento óptimo" significa "el mejor punto de un río para la explotación hidroeléctrica desde el punto de vista técnico".

El concepto de "aprovechamiento óptimo" va al encuentro de la idea de Raffestin (1993), quien señala que "el hombre no se interesa por la materia como masa inerte indiferenciada, sino en la medida en que ésta posee propie- 
dades que corresponden a utilidades"; en este caso, la generación de energía. Más allá del aspecto técnico, es importante tener en cuenta otra afirmación del mismo autor en el sentido de que "la relación que hace surgir un recurso no es puramente instrumental, sino también política" (Raffestin, 1993: 225). Por lo tanto, en la medida en que esos lugares son determinados, se configuran posibles escenarios de conflicto entre agentes sociales que distinguimos bajo la luz de las dos tendencias mencionadas en la sección anterior.

Una vez determinada la ubicación de este "aprovechamiento óptimo", la respectiva SPE busca hacer accesible este espacio privilegiado para la instalación de la hidroeléctrica. Nicolas defiende que "cada apropiación del espacio implica una nueva atribución de coherencia, de una nueva lógica que adquiere contenido con un devenir social específico, en el cual se entretejen lo individual y lo colectivo" (Nicolas, 1996: 85) . En este sentido, la instalación de una hidroeléctrica significa la reconfiguración geográfica y social de este lugar, según la perspectiva aquí propuesta, respecto del cual coexisten dos lógicas distintas de apropiación. Una de ellas es la de los afectados que, como agricultores familiares, viven bajo un "modelo tecnológico sumamente simple, aunque a la vez complejo, ya que no solamente no está sometido a la búsqueda de transformaciones permanentes sino que se constituye a través de lenta evolución y, sobre todo, transforma la adaptación del modelo tecnológico a las condiciones del espacio" (Nicolas, 1996: 87). Estos agricultores y la manutención de este modelo de apropiación del espacio son representados en la problemática hidroeléctrica principalmente por el Movimiento de los Afectados por Represas (Movimento dos Atingidos por Barragens, MAB por sus siglas en portugués). La otra lógica está en armonía con las SPE, basada en una "visión desarrollista" sobre la cual "se realiza un trabajo tecnológico no destinado a mejorar la permanencia de las formas espaciotemporales, sino orientado a acelerar el cambio e intensificar temporalmente la apropiación del espacio" (Nicolas, 1996: 88).

El conflicto entre estas dos lógicas de apropiación del espacio, en armonía con los dos proyectos políticos distintos, coexisten o disputan en estos lugares de "aprovechamiento óptimo" donde se pretenden realizar los proyectos de las hidroeléctricas. De esta manera, configuran relaciones de poder que merecen un análisis específico a partir de cada hidroeléctrica, pero que acaban asumiendo la "dimensión de una malla", que "nunca es, o casi nunca, aleatoria, pues hace cristalizar todo un conjunto de factores, de los cuales unos son físicos, mientras otros son humanos: económicos, políticos, sociales y culturales". Es desde esta óptica relacional como consideramos cada planta hidroeléctrica "en tanto puntos de poder" o puntos que "se definen mejor en términos relativos más que en términos absolutos" (Raffestin, 1993: 155-156). 
Retomando la idea de que la instalación de hidroeléctricas comprende un proceso social amplio, la "malla" que corresponde a este proceso está formada por puntos identificados por las plantas o centrales hidroeléctricas (UHE) y por los Reasentamientos Rurales Colectivos (RRC). Al ser el desplazamiento poblacional algo forzoso e inherente a esas obras a gran escala, cada hidroeléctrica o reasentamiento puede originar una nueva ubicación o "punto de poder" en la medida en que las poblaciones reubicadas se reagrupan muchas veces en localidades próximas a hidroeléctricas futuras. De esta manera, el proceso social referente a la hidroelectricidad en la cuenca hidrográfica del Río Uruguay fue configurando esta "malla de análisis" que puede ser visualizada a través de la figura 1, que reúne las hidroeléctricas y los respectivos reasentamientos rurales colectivos.

El mapa ilustra nuestro análisis sobre el caso de la cuenca del Río Uruguay. Asumiendo el análisis en la perspectiva de una "malla", cada "punto de poder" puede ser tomado a través de una hidroeléctrica o de un reasentamiento. La Planta Hidroeléctrica de Energía (UHE) representa la cristalización de la lógica desarrollista (neoliberal), por el hecho de ser el lugar donde se encuentra anclado un proyecto que reúne a la iniciativa privada con empresas públicas y privadas de diferentes partes del mundo, que actúan en este lugar a través de una SPE. El desplazamiento forzoso, consecuencia de la apropiación del espacio para la instalación de la hidroeléctrica, provoca el reagrupamiento de agricultores en los RRC, lo cual representa la cristalización de una tendencia política democrático-participativa a través de las acciones del MAB.

La coexistencia de estos puntos de poder se fue estableciendo en la medida en que se desarrollaba el proceso social inherente a la hidroelectricidad en la cuenca, a la vez que cada nuevo punto representa también un nuevo momento del conflicto. Una vez presentada la idea de "malla de análisis" y sus respectivos "puntos de poder", en las secciones siguientes haremos una aproximación más específica a los agentes protagonistas de acuerdo con sus acciones e identificación con las respectivas tendencias políticas y de apropiación del espacio.

\section{Las hidroeléctricas como "puntos de poder" de las Sociedades de Propósitos Específicos (SPE)}

El sector eléctrico se estructuró en Brasil a partir de las empresas de Estados Unidos y Europa. En 1889 entró en operación la primera planta hidroeléctrica nacional, y la primera de América del Sur, considerada de gran tamaño. La UHE Marmelos-Zero (4MW de potencia), en el río Paraibuna, municipio de 


\section{Figura 1}

Mapa de la cuenca hidrográfica del Río Uruguay

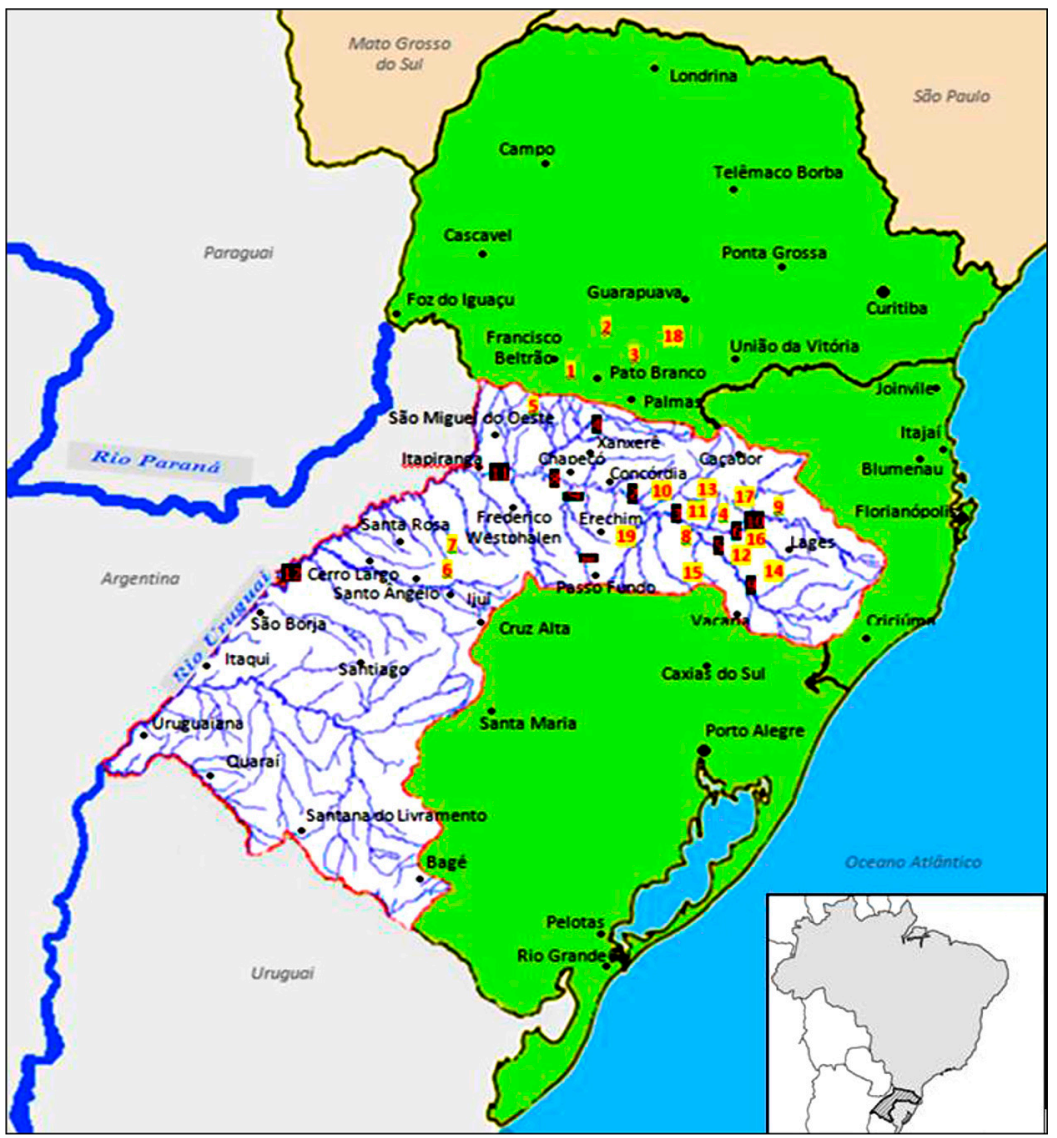

Las principales hidroeléctricas de la cuenca hidrográfica del Río Uruguay y los respectivos reasentamientos: 1. UHE Passo Fundo, 2. UHE Itá (1. RRC Marmeleiro, 2. RRC Chopinzinho, 3. RRC Honório Serpa, 4. RRC Campos Novos, 5. RRC Campo Erê, 6. RRC Catuípe, 7. RRC Chiapetta, 18. RRC Mangueirinha); 3. UHE Machadinho (8. RRC Barracão, 9. RRC Curitibanos, 4. RRC Campos Novos, 10. RRC Capinzal, 19. RRC Erechim, 11. RRC Zortéa); 4. Quebra-Queixo; 5. UHE Barra Grande (12. RRC Campo Belo do Sul, 13. RRC Anita Garibaldi, 14. RRC Capão Alto, 15. RRC Esmeralda); 6. UHE Campos Novos (16. RRC Celso Ramos, 17. RRC Cerro Negro); 7. UHE Monjolinho, 8. uHE Foz do Chapecó (18. RRC Mangueirinha), 9. uHE Pai Querê, 10. uHE Garibaldi, 11. UHE Itapiranga, 12. UHE Garabi.

Fuente: elaborado por el autor. 
Juiz de Fora (MG), fue instalada a través de la unión entre el Estado y la iniciativa privada, ya que la Compañía Minera de Electricidad era controlada por el industrial Bernardo Mascarenhas (Mielnik y Neves, 1988: 18). En los primeros años republicanos de Brasil, la Constitución (1891) preveía que los recursos naturales, incluso los hídricos, serían accesorios a la propiedad de tierra; luego entonces, de derecho de explotación de los propietarios. Con la llegada del capital extranjero ya a finales del siglo XIX, las iniciativas locales se verían centralizadas de manera gradual en torno a dos empresas principales, la Light en el eje Rio-São Paulo y la Amforp, que también actuaba en São Paulo (en el interior) y otras capitales.

La crisis cafetalera debilitó a las oligarquías locales y la Revolución de 1930 llevó a Getúlio Vargas al poder. En la política de industrialización y nacionalismo de Vargas, el sector de energía se tenía como sector estratégico y la disponibilidad de energía era uno de los obstáculos a ser superados, ya que el carbón de piedra, combustible principal de la industria moderna, se presentaba como de "calidad inferior" y de "explotación difícil y precaria" en Brasil (Prado Júnior, 2004: 257). La hidroelectricidad despuntó como alternativa y a través del Código de Aguas (1934) la concesión de aprovechamientos hídricos, públicos o privados solamente sucedería a través del gobierno federal.

Este proceso de avance estatal no se dio sin una fuerte resistencia del lobby de las empresas extranjeras (CMEB, 1988: 81-84). En 1960 fue creado el Ministerio de Minas y Energía (MME) y al año siguiente surgió ELETROBRAS (Centrales Eléctricas Brasileñas, S.A.), un holding organizado en cuatro subsidiarias regionales: CHESF (Nordeste), Furnas (Sureste), ELETROSUL (Sur) y la ELETRO NORTE (Norte). Gradualmente el Estado absorbió la iniciativa privada a través de ELETROBRAS.

Al final de la década de 1970, el sector hidroeléctrico brasileño se consolidó a través de la articulación industrial de tres segmentos: estudios y proyectos, construcción civil y equipos eléctricos. Sin llegar a discutir aquí los límites entre la competencia y el monopolio, podemos decir que las empresas como ENGEVIX, en el área de investigaciones y proyectos para la viabilidad de la instalación de hidroeléctricas; la compañía Camargo Correa, en el área de la construcción propiamente dicha de las represas: y las compañías de materiales eléctricos que van desde turbinas hasta electrodomésticos, como Alstom y Voith-Siemens, alcanzaron un lugar destacado en la instalación de hidroeléctricas, y obtuvieron gran impulso en sus negocios en virtud del creciente número de plantas en instalación, tales como las UHE de Paulo Afonso, Tres Marias, Furnas, Itaipu, Sobradinho, Tucuruí, Salto Osorio y Salto Santiago, que le aportaron al periodo un gran paso en la estructuración del sector hidroeléc- 
trico brasileño en lo que respecta al parque generador (Lima, Barbalho y Carvalho, 1995: 166).

Inspirado en el neoliberalismo, el Plan Nacional de Desestatización (1990) promovió en Brasil el mayor paquete de privatización del mundo en ese periodo, que llegó a $48.3 \%$ de transferencia de capital estatal a la esfera privada, de la cual la mayor parte incluyó el sector de energía eléctrica, que correspondió a 31\% del capital transferido (Gonçalves Júnior, 2007: 25). En lo relativo a las privatizaciones, ELETROSUL, responsable de la hidroelectricidad en la cuenca del Río Uruguay, se dividió en dos partes: ELETROsul (estatal), responsable de la transmisión de energía, y GERASUL (iniciativa privada), responsable de la generación, y que asumió todas las plantas hidroeléctricas de ELETROSUL en operación o en proyecto. En 1995, el Estado asumió definitivamente la condición de socio de la iniciativa privada en la instalación de hidroeléctricas a través de las Asociaciones Público Privadas (Parcerias Público Privadas, PpP por sus siglas en portugués), al tiempo que los proyectos a gran escala, como las hidroeléctricas, comenzaron a ser dirigidos por las SPE, que fueron creadas en virtud de la obra (planta) que pretendan instalar y operar. Al año siguiente fue creada la Agencia Nacional de Energía Eléctrica (ANEEL), un organismo independiente bajo régimen especial, vinculado con el Ministerio de Minas y Energía y cuya finalidad era regular y fiscalizar la producción, transmisión, distribución y comercialización de energía eléctrica.

En la estructuración del sistema hidroeléctrico brasileño se distinguen tres etapas; la primera, desde fines del siglo XIX hasta principios de la década de 1930; la segunda, de la década de 1930 hasta principios de 1990, cuando comienza una tercera etapa que abarca hasta la actualidad. La primera y tercera etapas son predominantemente de la esfera privada, mientras que la intermedia se caracterizó por el predominio estatal. Esta afirmación puede mantenerse de forma genérica; sin embargo, es importante señalar que desde el primer proyecto en 1883, pasando por las hidroeléctricas de la segunda etapa, hasta la etapa actual, podemos identificar cierta simbiosis entre lo estatal y lo privado, ya sea en la forma de asociarse cristalizada en los consorcios, o en la relaciones puntuales para servicios especializados, que acaban sugiriendo un abordaje de la cuestión mas allá de la dicotomía Estado/iniciativa privada.

En la perspectiva de la malla de análisis aquí propuesta, esta simbiosis es perceptible en las hidroeléctricas en tanto obras a gran escala que representan puntos de poder neoliberal, pues significan "oportunidades únicas para promoverse, en un contexto reglamentado, la articulación del capital internacional y nacional bajo la supervisión de diferentes Estados nacionales y de organizaciones supranacionales", pues el "consorcio es la entidad 
social, económica y política concreta que opera esta articulación" (Ribeiro, 1991: 102).

Aunque las hidroeléctricas representen estos puntos de poder, en los cuales cristalizan las asociaciones bajo la lógica neoliberal, esto no significa que estas sociedades se vuelvan rígidas. Al contrario, lo que merece destacarse es la capacidad de "desterritorialización" inherente a estas "estructuras de poder económico, político, social y cultural internacionales, mundiales o globales descentralizadas" para hacerse "presentes en muchos lugares, naciones, continentes, y que parecen fluctuar por sobre los Estados y fronteras, las monedas, lenguas, grupos y clases, movimientos sociales y partidos políticos" (Ianni, 1997: 93-94). Estas estructuras, que según Ianni (1997) parecen "fluctuar" por sobre las diferentes partes del globo, se relacionan con los Estados nacionales a partir de una adaptación mutua.

En el caso de América Latina, y especialmente en referencia al sector hidroeléctrico, esta desterritorialización que hace cristalizar el poder en diferentes puntos puede ser percibida a través del trabajo de Verdum (2007), en el que el autor apunta hacia la Iniciativa para la Integración de la Infraestructura Regional Sudamericana (IIRSA) y el Plan de Aceleración del Crecimiento (PAC), como los caminos de esa relación a través de "estrategias de desarro1lo" que buscan fomentar proyectos a gran escala que tienen en la energía uno de sus puntos fundamentales. La IIRSA comprende un foro de integración de América del Sur firmado en septiembre del año 2000, en Brasilia, que reunió a doce países sudamericanos con el objetivo de crear la "definición de una estrategia de trabajo conjunto para integrar las infraestructuras nacionales" (Verdum, 2007: 17-18). Además de los Estados, el autor destaca el papel de las instituciones financieras, como el Banco Internacional de Reconstrucción y Desarrollo (BIRD), el Banco Nacional de Desarrollo Económico y Social (BNDES), aparte de empresas de gran tamaño, entre las que destacan la General Electric (GE), América Latina Logística (ALL), Vale do Rio Doce, Odebrecht, Petrobras, Andrade Gutiérrez y Queiroz Galvão (Verdum, 2007: 22), y vale la pena subrayar que algunas de éstas se encuentran involucradas directamente con hidroeléctricas en la cuenca del Río Uruguay, región en la que basamos nuestro análisis. Desde esta perspectiva, podemos comprender que los proyectos a gran escala como las hidroeléctricas tienen que ver con una red de agentes en diferentes espacios que están ligados a partir de varias obras que componen un proyecto mayor, en este caso continental; lo cual, en consecuencia, forma parte de un proyecto todavía más amplio insertado en la lógica del capital global.

Para que comprendamos esta relación entre Estado y capital resultan importantes las ideas de dos autores: Poulantzas (1981) y Castells (2003). Pou- 
lantzas considera a los Estados como "la condensación de una relación de fuerzas entre las fracciones de clase tal y cómo ellas se expresan, siempre de manera específica, en el seno del Estado, lo que significa que el Estado está constituido-dividido de lado a lado por las contradicciones de clase". De esta manera, el autor defiende que el Estado "no es, y no podrá ser jamás, como en las concepciones del Estado-cosa o Sujeto, un bloque monolítico sin fisuras, cuya política se instaura de cualquier manera a pesar de las contradicciones, sino que él mismo está dividido". Este autor señala que el Estado está formado por contradicciones de clase que estarían "presentes en su estructura material, y arman así su organización: la política del Estado es el efecto de su funcionamiento en el seno del Estado" (Poulantzas, 1981: 152-152). En la misma línea, pero refiriéndose al capital privado, Castells afirma que "con la rápida transformación tecnológica, las redes, no las empresas, se vuelven la unidad real de operación". Entonces, él utiliza el concepto de "empresa red" para caracterizar "aquella forma específica de empresa cuyo sistema de medios está constituido por la intersección de segmentos de sistemas autónomos de objetivos" (Castells, 2003: 232).

Las afirmaciones de los autores, además de corroborar la importancia del “consorcio" presentado por Ribeiro (1991) para el entendimiento de la cuestión, señalan la perspectiva relacional que en este trabajo enfatizamos a través de la simbiosis entre lo estatal y lo privado. Entonces, a partir de las ideas de los autores citados arriba, comprendemos la naturaleza relacional de la instalación de las hidroeléctricas, tanto en lo que respecta a las escalas de acción — global/local — como a los agentes sociales involucrados. Para ilustrar lo que estamos hablando y avanzar sobre el caso específico, presentamos el cuadro de los accionistas de las principales hidroeléctricas de la cuenca del Río Uruguay (figura 2):

El cuadro permite observar la repetición de consorcios en diferentes centrales. Aunque nuestro análisis tenga un recorte empírico en la cuenca del Uruguay, si ampliamos el cuadro hacia la esfera nacional o hacia la continental, observaremos su repetición. Lo que es importante señalar es que el know how y la flexibilidad del capital de las empresas privadas se alía al monopolio de la fuerza legal del Estado en cada punto donde se pretende instalar una hidroeléctrica. Aunque tengamos conciencia de que los proyectos globales son más complejos de lo que presenta esta sección, tratamos de señalar algunos componentes de la concepción de una hidroeléctrica, en tanto punto de poder. Lo fundamental para nuestro análisis es comprender, aunque sea de manera sintética, elementos de esta cristalización de empresas estatales y privadas nacionales e internacionales en SPE. Asimismo, queremos demostrar que éstas actúan de manera que se identifican con un proyecto neoliberal y, sin la pre- 
Figura 2

Accionistas de las principales UHE de la cuenca del Río Uruguay

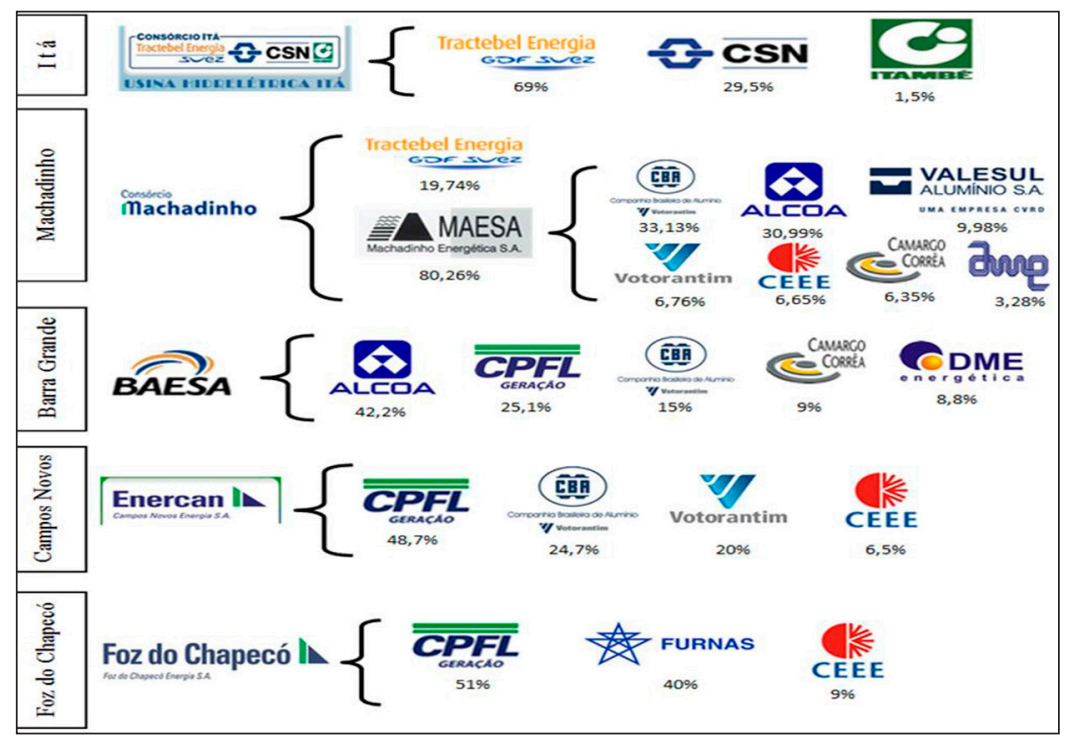

Fuente: elaborada por el autor.

tensión de rigidizar el análisis, sugerir la naturaleza de la acción de estos agentes, en lo que se refiere al conflicto inherente a las obras de gran escala, como las hidroeléctricas.

Presentadas la trayectoria y la naturaleza de las SPE, podemos comprender de qué manera esto se refleja en la cuestión hidroeléctrica, sobre todo en la movilización social como consecuencia de la instalación de las centrales. Lo que Tilly (1977) llama "polity model" ("modelo de sistema político"), coloca al gobierno como punto privilegiado de análisis sobre los escenarios, y contempla "adversarios y miembros del gobierno a través de coaliciones y lucha por el poder" (Tilly, 1977, 4: 1). El gobierno asume un lugar destacado en el análisis por ser éste un agente monopolizador de la fuerza legal. De esa manera contribuye significativamente a la "facilitación" o "represión" de modelos de movilizaciones para acciones colectivas. El autor presenta dos acciones de gobierno en el sentido de la facilitación o de la represión, que son perfectamente consistentes con lo que acostumbramos observar en 
las investigaciones empíricas sobre las hidroeléctricas; es decir, el control de flujo de información sobre los proyectos, intensificando o reduciendo las penalizaciones de aquellos que se movilizan y actúan socialmente (Tilly, 1977, 4: 3). En lo que se refiere a la cuenca del Río Uruguay, Locatelli (2014) demuestra que el control de información es decisivo para la movilización social a partir del momento en que limita la movilización social mediante la información y desinformación de las poblaciones locales. En lo referente a las sanciones, presentamos recientemente un análisis sobre lo que llamamos “criminalización de los movimientos sociales", la cual tiende a limitar drásticamente la acción colectiva (Rocha, 2014).

La "selectividad" del gobierno y la naturaleza de la "red" de las empresas fundamentan la naturaleza de las SPE y se encaminan hacia el análisis que Tilly (1977) hace acerca de la acción del gobierno considerando la relación entre el "poder" del gobierno, su "autoridad" y la "influencia" a la cual está sujeto. Apoyado en las ideas de William A. Gamson, el autor llama la atención hacia el hecho de que esta relación es importante para hacer la distinción entre el "poder para referirse al efecto de las autoridades sobre otras partes, y la influencia para referirse a los efectos de otras partes sobre esa autoridad" (Gamson, 1968, en Tilly, 1977: 4-29).

Para nuestro análisis es importante señalar que a través de las llamadas "sociedades público privadas", como sociedades especialmente creadas para llevar a cabo la instalación y operación de hidroeléctricas, la relación entre poder, autoridad e influencia se materializa en lo que el autor llama "political power" ("poder político"), que sería el poder de determinado agente en relación con el gobierno, ya sea sobre éste o con su apoyo (Tilly, 1977, 4: 30). Alternando funciones y papeles, el Estado y las empresas promueven la inserción de estos proyectos globales en las diferentes ubicaciones, reconfigurando estos espacios. En la próxima sección analizaremos la estructuración y naturaleza de los reasentamientos rurales colectivos (RRC) como contrapunto de este proceso.

\section{Los reasentamientos rurales colectivos como "puntos de poder" del MAB}

Siguiendo el análisis de la categoría de "malla", los reasentamientos son considerados los puntos de poder donde predominan las acciones del MAB, identificados, para fines del análisis, con un proyecto político democrático-participativo. De forma genérica, Bergamasco y Norder consideran los "asentamientos rurales" como la "creación de nuevas unidades de producción 
agrícola, por medio de políticas gubernamentales con el objeto de hacer un reordenamiento del uso de la tierra, en beneficio de los trabajadores rurales sin tierra o con poca tierra" (Bergamasco y Norder, 1996: 7-8). En la misma línea, los "reasentamientos de poblaciones afectadas por presas de plantas hidroeléctricas" son encuadrados por los autores como un tipo de asentamiento. Aunque consideremos el reasentamiento como un tipo de asentamiento, es necesaria una explicación más específica sobre el origen del término.

Durante el proceso de instalación de la UHE Itá del Río Uruguay, los líderes del movimiento social adoptaron de los técnicos de ELETROSUL el uso del término "reasentamiento". Así, "queda implícito que los 'afectados sin tierra' ya estaban asentados y, por lo tanto, van a ser 'reasentados', lo que, en verdad, no corresponde a la realidad de los trabajadores rurales sin tierra". Aunque técnicamente concordemos con que los "reasentamientos" corresponden a variaciones de "asentamientos", es importante señalar que, en el caso de las represas, "el hábito del lenguaje hizo que la palabra 'asentamiento' prácticamente desapareciera del vocabulario de los dirigentes, líderes y militantes del Movimiento de Afectados por Represas" (Moraes, 1994: 158). El uso del término "reasentamiento", que Moraes (1994) presentó con base en la investigación referente a la UHE Itá en la década de 1990, puede ser percibido, de acuerdo con la investigación empírica en que se basa este trabajo, como utilizado tanto por el consorcio como por el movimiento social en aquel sentido.

Los (re)asentamientos no acostumbran suceder de forma deliberada, pues corresponden a los intentos de respuesta frente a los conflictos sociales en el campo (Bergamasco y Norder, 1996). Considerando a la hidroelectricidad como proceso social que parte de la primera hidroeléctrica instalada en el Brasil (1883), podemos decir que hasta las décadas de los setenta y ochenta no había una planeación previa para el reasentamiento de las familias afectadas por represas. En ese periodo, la reubicación ocurría "en las vísperas de las inundaciones" o "casi simultáneamente a la subida de las aguas", conforme a lo ocurrido en los casos de Sobradinho e Itaparica (río São Francisco, en el estado de Pernambuco), en la década de los setenta y Tucuruí (río Tocantins, en el estado de Pará) e Itaipú (río Paraná, en el estado de Paraná), en la década de los ochenta (Bergamasco y Norder, 1996).

Anteriormente señalamos que las hidroeléctricas corresponden a oportunidades de cristalización de intereses de agentes mundiales. En lo relacionado con los grupos, Sidney Tarrow utiliza el concepto de "oportunidad" para comprender de qué manera las demandas de los grupos afloran a partir de un escenario oportuno originando "enfrentamientos políticos". Dice el autor que "la confrontación política surge como una reacción a los cambios en las 
oportunidades y restricciones políticas en que los participantes reaccionan a una variedad de incentivos: materiales e ideológicos, partidarios o basados en el grupo, de larga duración o en episodios (Tarrow, 2009: 38).

Sin embargo, un escenario de oportunidad no significa necesariamente que las confrontaciones políticas puedan surgir. Aun frente a las demandas de grupos, simples o cruciales, hay que distinguir entre "potencial de movilización" y "acción". El primero representa el estado de latencia de la confrontación, mientras que el segundo representa la movilización efectiva que lo promueve. En ese sentido, Tarrow presenta cinco aspectos que deben observarse para poder comprender de qué manera este paso de potencial hacia la acción puede ocurrir de manera general: "1) la apertura del acceso a la participación para nuevos actores: 2) la evidencia de realineación política al interior del sistema; 3) la aparición de aliados influyentes; 4) divisiones emergentes al interior de la élite; 5) el descenso en la capacidad del Estado para reprimir disidencias" (Tarrow, 2009: 105).

En lo relativo al MAB, Rothman (1996) presenta un análisis importante en la perspectiva de la oportunidad política. Sin restringirse a la escuela estadounidense, el autor presenta puntos que ayudan a entender cómo el MAB pasó de la capacidad para la acción a un escenario de oportunidad. Después de presentar puntualmente los ítems sugeridos por Tarrow (2009) y enriquecerlos con apuntes geográficos inherentes a la cuenca del Río Uruguay, Rothman sintetiza el análisis de la oportunidad política de esta manera:

Resumiendo, en el periodo 1979-83, hubo una estructura de oportunidad política favorable creciente: la apertura política permitió el acceso progresivo al sistema político; la fragmentación de la élite debilitó la posición de los grupos dominantes; la tendencia del uso de la represión por el régimen militar mostró señales de disminución; los grupos populares, libres de la tutela de los partidos populistas, desarrollaron formas más autónomas de organización; y varios movimientos populares se reforzaron en la fase creciente del ciclo de protesta. (Rothman, 1996: 117)

En otra oportunidad trataremos de examinar minuciosamente estos puntos de forma más detallada (Rocha, 2013). Por el momento, lo fundamental es comprender cómo este escenario de oportunidad política explica la movilización social que culminó en la creación del MAB. Después retomaremos este aspecto de oportunidad y restricción de la movilización. Por ahora, además de la identificación del escenario de oportunidad cuando se crea el MAB, el análisis de Rothman llama la atención hacia otro factor importante para nuestro análisis: la idea de los "ciclos de protesta" que abordaremos bajo la denominación dada por Tarrow (2009); es decir, los "ciclos de confrontación". 
Los ciclos de confrontación están condicionados por los escenarios de oportunización y restricción política. Un ciclo se destaca por uno o más eventos de culminación que, para fines del análisis, ayudan a catalizar los elementos que están dispersos, pero interconectados a lo largo del proceso social correspondiente al referido ciclo. Tarrow presenta su definición del término como "una fase del conflicto acentuado que atraviesa un sistema social". En el mismo párrafo anota elementos constituyentes del ciclo, tales como: "una rápida difusión de la acción colectiva de sectores más movilizados hacia otros menos movilizados", "creación de cuadros interpretativos de acción colectiva, nuevos o transformados", "combinación de participación organizada y no organizada", capacidad de producir "externalidades que dan a los desafiantes al menos una ventaja temporal y permite que superen la debilidad en su base de recursos", lo que provoca que el Estado "monte amplias estrategias de reacción que son represivas o facilitadoras, o una combinación de ambas", y finalmente, un ciclo de confrontación "produce resultados generales que son más que la suma de los resultados de un agregado de eventos inconexos" (Tarrow, 2009: 182).

Es importante destacar que al analizar un ciclo y sus desdoblamientos es necesario cuidarse de no considerarlo "solamente como un 'contagio' de la acción colectiva para grupos similares y que hacen las mismas reivindicaciones a opositores equivalentes". El autor señala como una característica importante para el análisis la "difusión de la propensión a la acción colectiva" (Tarrow, 2009: 186). El título del libro, 1968: o ano que não terminou (1968: el año que no terminó), del periodista Zuenir Ventura, sirve como ejemplo de la relación entre ciclos de confrontaciones en diferentes partes del mundo que tienen, o pueden tener, relación dentro de un mismo ciclo. Ventura (1988) presenta una serie de crónicas sobre el periodo dictatorial brasileño con una delimitación temporal en el año 1968, pero teniendo como telón de fondo un ciclo que abarca desde Francia hasta Brasil a la luz del ciclo de confrontaciones destacado por los movimientos de mayo de 1968. Si se restringe nuestro análisis al caso brasileño, los 20 años entre 1968 y 1988 pueden ser tomados como un ciclo de enfrentamientos que culminó con el movimiento de las "Direitas Já" ("Derechas ya") y la apertura democrática. En ese ciclo está la cuestión de las represas que trataremos aquí teniendo como delimitación la cuenca del Río Uruguay, en el sur de Brasil.

La cuenca del Río Uruguay presenta relieve ondulado y suelo pedregoso, lo que dificulta la mecanización agrícola. La ocupación del espacio y el modo de vida coinciden con dicha configuración geográfica, ya que los agricultores tienen en la unidad familiar, pluriactividad y reciprocidad las bases de la organización de la vida social. Estos elementos fundamentan las palabras de Pi- 
ran (2001), cuando defiende el Alto Uruguay como "un lugar para la agricultura familiar". A partir de la configuración geográfica y social de la región se estructuró un parque agroindustrial que actualmente es referencia mundial en productos derivados del ganado porcino y las aves.

La agroindustria regional es importante para un registro histórico que consideramos está directamente relacionado con la cuestión hidroeléctrica. Resultó muy significativo en la economía a partir de finales del siglo XIX la crisis que la porcicultura atravesó a fines de la década de los años setenta y que se reflejaría de forma importante en el contexto político regional. Dicha crisis se desató a través de la supuesta contaminación de los cerdos por la llamada "peste porcina africana" que podía diseminarse por todo el país. Ante la sospecha de contaminación, desde septiembre de 1978 las propiedades identificadas eran interdictadas. Y los cerdos eran exterminados por pelotones del Ejército (Poli, 1999: 68).

El evento que involucra la porcicultura como principal actividad económica de la región significó un duro golpe para los pequeños productores, lo que levantó la sospecha de que dicha enfermedad y los abatimientos relacionados con la misma serían parte de una estrategia del capital para debilitar la producción autónoma de cerdos. A partir de la mediación de sectores de la Iglesia (СРT) y de Sindicatos de Trabajadores Rurales (STR) de la región, se organizó una intensa movilización social que culminó en una manifestación que reunió a más de 20 mil personas en la ciudad de Chapecó-SC en octubre de 1979, que protestaban contra las condiciones de producción del sector, pero principalmente contra lo que se llegó a conocer como la "farsa de la peste porcina africana" (Poli, 1999: 70).

La movilización social ante la cuestión de los cerdos hizo que los abatimientos fueran disminuyendo poco a poco. No quedó definitivamente comprobada la existencia o el alcance de dicha enfermedad, lo que no cambia el hecho de que los abatimientos forzosos hubieran perjudicado a los pequeños productores. El registro de este evento es importante para indicar qué sucedió en la misma época en que la ELETROSUl publicó un "Estudio del Inventario Hidroeléctrico de la Cuenca del Río Uruguay" (octubre de 1979), que preveía la construcción de 22 plantas hidroeléctricas en la mencionada cuenca, lo que significaría que grandes áreas de tierra serían inundadas en la región. Dicho de otra manera, para los agricultores familiares locales en aquella época, además del problema del abatimiento de los cerdos, se sumaba la amenaza de la expropiación.

El mencionado estudio, realizado por ELETROSUL, fue llevado al conocimiento de la opinión publica mediante la acción de grupos que también militaban en el contexto nacional de la dictadura militar, a saber, las iglesias, 
sindicatos y universidades. En el caso de la cuenca del Río Uruguay, segmentos de la Iglesia Evangélica de Confesión Luterana en Brasil (IECLB), algunos sindicatos de trabajadores rurales, y la Fundación Alto Uruguay para la Investigación y la Enseñanza Superior (FAPES), de Erechim-RS (actual URI), pueden ser considerados como los principales mediadores de la cuestión hidroeléctrica desde el plano teórico hasta la movilización de la población afectada que habitaba en la cuenca.

A partir de las primeras acciones encaminadas a la organización de un movimiento social cohesivo habría que retomar el escenario de oportunización política que, si bien no determinaba la eclosión de movimientos de esta naturaleza, por lo menos favorecía su estructuración. En este contexto, el poder de represión del Estado fue poco a poco disminuyendo en relación con el auge del periodo militar. La Ley de Amnistía, de agosto de 1979, permitió el regreso de los exiliados políticos al país reforzando el activismo en las diversas causas sociales. En noviembre de ese mismo año, el fin del bipartidismo promovió la división de las élites, lo que provocó el debilitamiento de las oligarquías en Rio Grande do Sul. En 1983, los partidos de oposición en la Asamblea Legislativa investigaron y publicaron un informe sobre la cuestión de las represas, además de poner instalaciones a disposición de las Asambleas para la promoción del $\mathrm{I}^{\mathrm{o}}$ Encuentro Estatal sobre la Construcción de Represas en la Cuenca del Río Uruguay, que reunió a diferentes segmentos sociales en torno a esta cuestión. Esta coyuntura política, aunada a eventos locales, significó un ambiente favorable para el surgimiento de un movimiento social ante el proyecto de la empresa hidroeléctrica en la región.

Para el análisis de la emergencia de un movimiento frente a las hidroeléctricas en el referido contexto vale la pena que retomemos las ideas de Tilly (1977) para que entendamos en qué condiciones se dio esta movilización. En la sección anterior utilizamos el concepto de polity model para estudiar el escenario de oportunización por parte de la perspectiva del Estado. Ahora utilizamos el de movilization model ("modelo de movilización"), que el mismo autor utiliza para analizar el comportamiento de un único agente al pensar su movilización. El autor enlista cinco aspectos que necesitan ser considerados en la toma de decisiones, a saber: 1) intereses, "las ventajas o desventajas comunes que puedan llegar a la población en cuestión, como consecuencia de varias posibles interacciones con otras poblaciones"; 2) organización, "la medida de identidad común y de la estructura unificadora entre individuos en la población"; 3) movilización, "la medida de los recursos bajo el control colectivo del grupo"; 4) acción colectiva, "el grado de acción conjunta de un grupo en busca de fines comunes, como un proceso, de la propia acción conjunta"; 5) oportunidad, "la relación entre los intereses de 
la población y del estado actual del mundo en torno al mismo" (Tilly, 1977, 3: 4-5).

El último aspecto que discutimos anteriormente fue corroborar el escenario de oportunidad política vigente en Brasil de fines de la década de 1970. Sobre los "intereses", la posibilidad de la probable pérdida de tierras por la inundación, sumada al episodio relacionado con la porcicultura, pesó en la decisión de la movilización. La “organización”, “movilización” y “acción colectiva" pueden ser identificadas en acciones más expresivas de mediadores fundamentales en aquel contexto. La Iglesia católica colaboró a través del reclutamiento de participantes para el movimiento social a través de sectores de la Iglesia como la Comisión Pastoral da Terra (CPT), Pastoral da Juventude Rural (PJR) y Ministério Eucarístico, así como la utilización de estaciones de radio en municipios afectados como Concordia, Marcelino Ramos y Aratiba, y la disponibilidad de personal para la organización del movimiento a través de los llamados "liberados". ${ }^{3}$ La Iglesia Evangélica de Confesión Luterana en Brasil (ECLB) sirvió de canal de conexión entre los afectados de la cuenca del Río Uruguay con otras localidades como Itaipu y Sobradinho, intermedió un apoyo financiero de la organización evangélica alemana Brot Fur die Welt (Pan Para el Mundo), además de "liberar" personal para la organización del movimiento social. La Fundación de Apoyo para la Investigación y la Enseñanza Superior (Fundação de Apoio à Pesquisa e Ensino Superior, FAPES por sus siglas en portugués) y la Universidad de la ciudad de Erechim, además de la investigación de los impactos socioeconómicos, importantes para la fundamentación de la movilización y organización en torno al problema, hicieron que hubiera recursos disponibles de dos ONG: de la francesa Comité Católico Contra el Hambre y por el Desarrollo (CCFD) y de la alemana Obra Episcopal de la Iglesia Católica de Alemania para la Cooperación al Desarrollo (MISEREOR). Además de estas organizaciones fue importante la actuación de los Sindicatos de Trabajadores Rurales (STR), que a través de una perspectiva de "sindicalismo combativo" establecían una conexión más efectiva entre estas instituciones y los trabajadores rurales, además de hacer disponibles las estructuras físicas de los sindicatos para la organización del movimiento social (Rothman, 1996).

A partir de esta movilización en torno a la cuestión hidroeléctrica en la cuenca del Río Uruguay, podemos considerar como marco oficial de la orga-

${ }^{3}$ La figura del "liberado" se refiere a aquella persona que pertenecía a los cuadros de instituciones como las Iglesias católicas e IECLB, pero eran cedidos para otras instituciones, en este caso, para la organización del movimiento social contrario a las represas, teniendo importancia tanto por la experiencia y preparación para las tarifas designadas, como por el hecho de personificar la institución de origen en las cuestiones en que se involucraban. 
nización del movimiento social un evento que reunió a aproximadamente 350 agricultores familiares en Concordia (SC), el día 24 de abril de 1979, fecha en que los participantes formalizaron la Comisión Regional de los Afectados por Represas (Comissão Regional do Atingidos por Barragens, CRAB por sus siglas en portugués). La evolución del movimiento social sucedió de manera paralela a la presentación de nuevos proyectos hidroeléctricos por todo Brasil, tanto que el Plan 2010, elaborado por ELETROBRAS, preveía la construcción de cerca de 200 plantas hidroeléctricas por todo el país. Así, el movimiento se articuló y en marzo de 1991, en la ciudad de Brasilia, se celebró el " $1{ }^{\text {er }}$ Congreso Nacional de los Afectados por Represas", donde se hizo oficial el Movimiento Nacional de los Afectados por Represas (MAB), mientras que la CRAB comenzó a responder como MAB/Región Sur, integrada al movimiento nacional.

Considerando que el movimiento social frente a las represas puede ser identificado en diferentes regiones de Brasil, fue en el caso de UHE Ita donde se observó un gran salto cualitativo en relación con el reubicación poblacional, en especial al RRC; tanto que, como ya señalamos, el término tuvo su origen en esta circunstancia. La lucha por la tierra en aquella hidroeléctrica se dio todavía bajo la organización de la CRAB. El movimiento social firmó un acuerdo histórico con ELETROSUL el 17 de octubre de 1987, que no fue firmado por el presidente de la empresa hasta el 29 de octubre y por el ministro de Minas y Energía el 6 de noviembre, siempre a costa de la presión popular (Moraes, 1994: 167). Fruto de la misma lucha, el movimiento social logró la participación en un Grupo de Trabajo que junto con representantes de cooperativas y técnicos de ELETROSUL elaboraron un "proyecto de reasentamiento". Fue a través de esta iniciativa como se hizo viable un primer núcleo formado por 27 familias que fueron reasentadas en el municipio de Marmeleiro-PR, y al siguiente año "ELETROSUL interrumpió todas las negociaciones, tanto las indemnizaciones como los reasentamientos" (Moraes, 1994: 169).

El referido proyecto de reasentamiento puede ser considerado un parteaguas en la reubicación poblacional originada por las hidroeléctricas. Sin embargo, por tratarse de "un documento hecho a muchas manos", "de la total y masiva presencia de técnicos de la empresa", y teniendo a la vista que "el proyecto fue construido con base en el modelo que se quería en términos de infraestructura", el sentido político de estos reasentamientos acabó disminuido, ya sea porque en "las opciones del movimiento aparecen mezcladas las del Estado", o porque la presencia de los técnicos de los consorcios "dificulta aún más la comprensión del derecho a la tierra como resultante de la lucha de los afectados mediada por la CRAB" (Moraes, 1994: 170, 172). 
En este sentido, una diferencia más específica entre los asentamientos del Movimiento de los Trabajadores Sin Tierra (MST) y los reasentamientos del MAB merece ser señalada. Mientras que los primeros son fruto de movilizaciones, principalmente a través de los "campamentos" de los sin tierra, los últimos son resultado de un choque entre la empresa constructora del embalse y los afectados sin tierra y/o propietarios. Así, mientras que MST califica la lucha política a través del "tiempo de acampado" (Loera, 2006), el $\mathrm{MAB}$, aunque también desarrolle un proceso de resistencia ante las presas, no dispone de la misma oportunización, ya que la "militancia" se da simultáneamente a la posibilidad de "negociación" (Rocha, 2010). Entonces, es posible relativizar la naturaleza de los reasentamientos como puntos de movilización política del MAB en los modelos, como sucede con el MST. Además de esta diferencia, reforzamos la naturaleza relacional de nuestro análisis tomando los reasentamientos como "procesos sociales que involucran periodos de tiempo significativos", pues éstos "son altamente susceptibles al cambio en las condiciones iniciales". En ese sentido, los reasentamientos "evolucionan en un campo dominado por relaciones de poder y son de naturaleza esencialmente política" (Bartolome, 2000). Esta dimensión temporal significa que "la configuración de factores que pueden caracterizar un proceso en su fase inicial está abierto a cambios que se originan no sólo en su interior sino también en su exterior" (Bartolome, 2000: 163-165). Asimismo, "el simple hecho de ser afectado por un proyecto no define a un grupo en el sentido sociológico, a saber, eso no deja implícita la existencia de atributos comunes, ni de objetivos comunes". Dicho de otra manera, tomando al MST como medida, la situación de los afectados por presas se configura como algo más complejo, en el que la movilización y sus resultados son todavía más susceptibles al cambio.

En la sección anterior tratamos a las hidroeléctricas como "cristalización" de proyectos neoliberales. Por eso, los reasentamientos merecen ser relativizados en su naturaleza democrático-participativa. Éstos se conciben a partir de relaciones de poder entre el MAB y la SPE en cada hidroeléctrica. Si hiciéramos una rápida retrospectiva, en el caso de la UHE Itá (1990), al tiempo que los reasentamientos representaron conquistas del movimiento social, también fueron comprendidos como beneficios derivados de la instalación de la central. En el caso de la UHE Campos Novos (2005), por ejemplo, los reasentamientos fueron instalados a partir de la mediación entre la SPE y una asociación que disputó, y suplantó, la representatividad del MAB. En el caso de la UHE Foz do Chapecó (2010), no obstante el esfuerzo del movimiento social, únicamente 40 familias fueron reasentadas a partir de movilizaciones del MAB. Estas diferencias reflejan el cambio de contexto (privatización del 
sector eléctrico, relaciones entre mediadores como los sindicatos, Iglesias y universidades, y el ascenso del Partido de los Trabajadores al gobierno) y, en consecuencia, el movimiento social también cambió su forma de actuar (Rocha, 2013).

En la perspectiva adoptada en esta discusión, los Reasentamientos Rurales Colectivos reúnen familias de pequeños agricultores que en la mayoría de los casos son organizados bajo la égida del MAB ante el desplazamiento forzoso derivado de la instalación de hidroeléctricas. Esto pone a los reasentamientos como posibles "puntos de poder" en la perspectiva de un proyecto democrático participativo. Considerando que la cuenca del Río Uruguay comprende una región con más de 30 proyectos hidroeléctricos ya instalados o en vías de instalación, y 29 reasentamientos derivados de esos proyectos, es importante que comprendamos en qué medida estos puntos influyen en las relaciones de poder que componen la "red" de análisis correspondiente a la cuenca (figura 1).

\section{La "multiterritorializacion" del conflicto en la cuenca del Uruguay}

Las hidroeléctricas comprenden proyectos neoliberales anclados en determinados lugares por medio de acciones de las SPE que buscan apropiarse de esos espacios. Consecuentemente, las poblaciones locales permanecen pasivas con respecto al desplazamiento forzoso a través de modalidades de reubicación, de entre las cuales el RRC es el preferido por el MAB por mantener los vínculos anteriores de vecindad y por la posibilidad de tomar latifundios en áreas de agricultura familiar, modificando la lógica productiva. Por otro lado, la Carta de Crédito ${ }^{4}$ es la modalidad que más conviene a las SPE por la rapidez de salida del afectado del área que será utilizada por la hidroeléctrica y por representar un menor costo en relación con los reasentamientos.

Tanto las instalaciones de hidroeléctricas como las respectivas reubicaciones poblacionales provocan reconfiguraciones sociales y modifican los sentidos de las territorializaciones de los lugares. Observamos que ocurre una "multiterritorialización", que Haesbaert (2005) entiende como "una respuesta a este proceso identificado por muchos como 'desterritorialización"”. Según el autor, más allá de la pérdida de un territorio, el término propone la

${ }^{4}$ Nota: la carta de crédito consiste en una modalidad de reubicación en que la empresa que construye la hidroeléctrica pone a disposición una carta de crédito cuyo valor está calculado con base en un "inmueble rural hipotético", con área correspondiente al "módulo rural regional", independiente del tamaño del área de la propiedad afectada. En el caso de la cuenca del Uruguay el módulo es de 17 hectáreas. 
discusión acerca de la "complejidad de los procesos de (re)territorialización que constituyen territorios "mucho más múltiples", siendo que "estos procesos de (multi)territorialización necesitan ser especialmente entendidos por el potencial de perspectivas políticas innovadoras que ellos implican" (Haesbaert, 2005: 6774).

Los proyectos hidroeléctricos controlan los espacios donde se instalan mediante la mudanza obligatoria. Los consorcios de empresas posibilitan la actuación y el control de diferentes lugares al punto de ser llamados en la cuenca hidrográfica "los dueños del río Uruguay" (Paim y Ortiz, 2006: 56). Por otro lado, conviene verificar en qué medida los afectados representados por el MAB, más allá de la desterritorialización o de la reubicación simple en otro lugar, al reagruparse en reasentamientos, tienen la posibilidad de "espacialización" y "territorialización" bajo una perspectiva democráticoparticipativa.

Refiriéndose a los asentamientos del MST, Fernandes explica que "espacializar es conquistar nuevos espacios, nuevos lugares, nuevas experiencias, desarrollar nuevas formas de lucha y, por ende, nuevas conquistas, transformando la realidad, luchando por el futuro" (Fernandes, 1999: 136). En consecuencia, "el asentamiento es el territorio conquistado; es, por lo tanto, un nuevo recurso en la lucha por la tierra que significa parte de las conquistas posibles, sobre todo, la posibilidad de territorialización" (Fernandes, 1999: 136). De este modo, se evidencia una relación entre los términos "espacialización" y "territorialización" en el sentido de que "la fracción del territorio es conquistado en la espacialización de la lucha, como resultado del trabajo de formación y organización del movimiento. Así, el territorio conquistado es triunfo y posibilidad de su territorialización en la espacialización de la lucha por la tierra" (Fernandes, 1999: 241).

Al trasladar la idea al análisis del proceso social con relación a la reubicación poblacional, derivado de la hidroelectricidad, ante los intentos de territorialización o espacialización de la lucha, buscaremos comprender en qué medida los reasentamientos pueden reflejarse en la multiterritorialización del conflicto entre el MAB y las SPE del sector hidroeléctrico. Haremos esto señalando, primero, de entre la modalidades de reubicación, cuál sería aquella en la que ocurre la mayor participación de afectados en movilizaciones ante los proyectos hidroeléctricos posteriores a su desplazamiento forzoso. Después, veremos las motivaciones de esas movilizaciones de forma que comprendamos su relación con la respectiva modalidad y consecuentemente con las acciones de sus proponentes.

Para sustentar teóricamente esta parte del análisis retomaremos las ideas del pionero de la teoría de la movilización de recursos, Mancur Olson. La 
perspectiva de este autor es importante en nuestro análisis por el hecho de que ayuda en la comprensión de la toma de decisiones en un grupo tan heterogéneo como el de los afectados por represas. En otra oportunidad (Rocha, 2010) defendimos la idea de una "condición" de afectado que se establece a través de una construcción social y asume la característica de transitoriedad. Pero para discutir la especificidad de la toma de decisiones de los afectados de participar o no de las movilizaciones después de haber sido reasentados en propiedades nuevas, las ideas de Olson parecen pertinentes. El autor explica que el hecho de que los intereses individuales estuvieran reunidos en un grupo no significa que ese grupo fuera a actuar en el mismo sentido, es necesario que haya algún incentivo o coerción para la acción (Olson, 2015: 14).

Para delimitar en cuál modalidad de reubicación poblacional tienen su origen los afectados que participan de las movilizaciones posteriores a sus reubicaciones, seleccionamos una pregunta de la encuesta que aplicamos a las familias reubicadas, hecho derivado de las cinco principales hidroeléctricas de la cuenca del Uruguay. La pregunta referida (núm. 48) fue: "Después de su reubicación, ¿usted participó en la movilización de apoyo a otros afectados?" Con base en las respuestas obtuvimos el cuadro 1.

El cuadro 1 ofrece una visión general de las modalidades y la participación de los afectados en movilizaciones sociales de cara a las hidroeléctricas futuras. Concentrando el análisis en las dos modalidades que nos interesan (RRC y CC destacadas en el cuadro), podemos observar que la modalidad de RRC se destaca como aquella en la que la mayor parte de los afectados, seis de cada 10, participan en movilizaciones después de ser reubicados. En contraposición, verificamos que la modalidad de carta de crédito presenta un índice menor de participación de los afectados después de la reubicación, siendo tan sólo tres de cada 10. Después, si consideramos tan sólo a los participantes en las movilizaciones, seis de cada 10 son originarios de reasentamientos, al tiempo que la participación de los indemnizados a través de carta de crédito decae a dos. La respuesta a la primera pregunta ayuda a la comprensión de la preferencia del MAB por la modalidad de RRC, al tiempo que la SPE prefiere la modalidad de carta de crédito.

Conforme lo presentado anteriormente, los factores como la aglomeración en el RRC, contrariamente a la distribución de los afectados - en el caso de las cartas de crédito- ha sido el principal factor para explicar la diferencia de la movilización de estas personas después de la reubicación (Rocha, 2010; 2013), aunque la superficialidad de estas afirmaciones nos llevó a seguir las orientaciones de Lieberman (2005), en las que el autor llama la atención hacia el "valor sinérgico" de un análisis que mezcla los métodos cuantitativos y cualitativos. El primero permite la observación del conjunto 


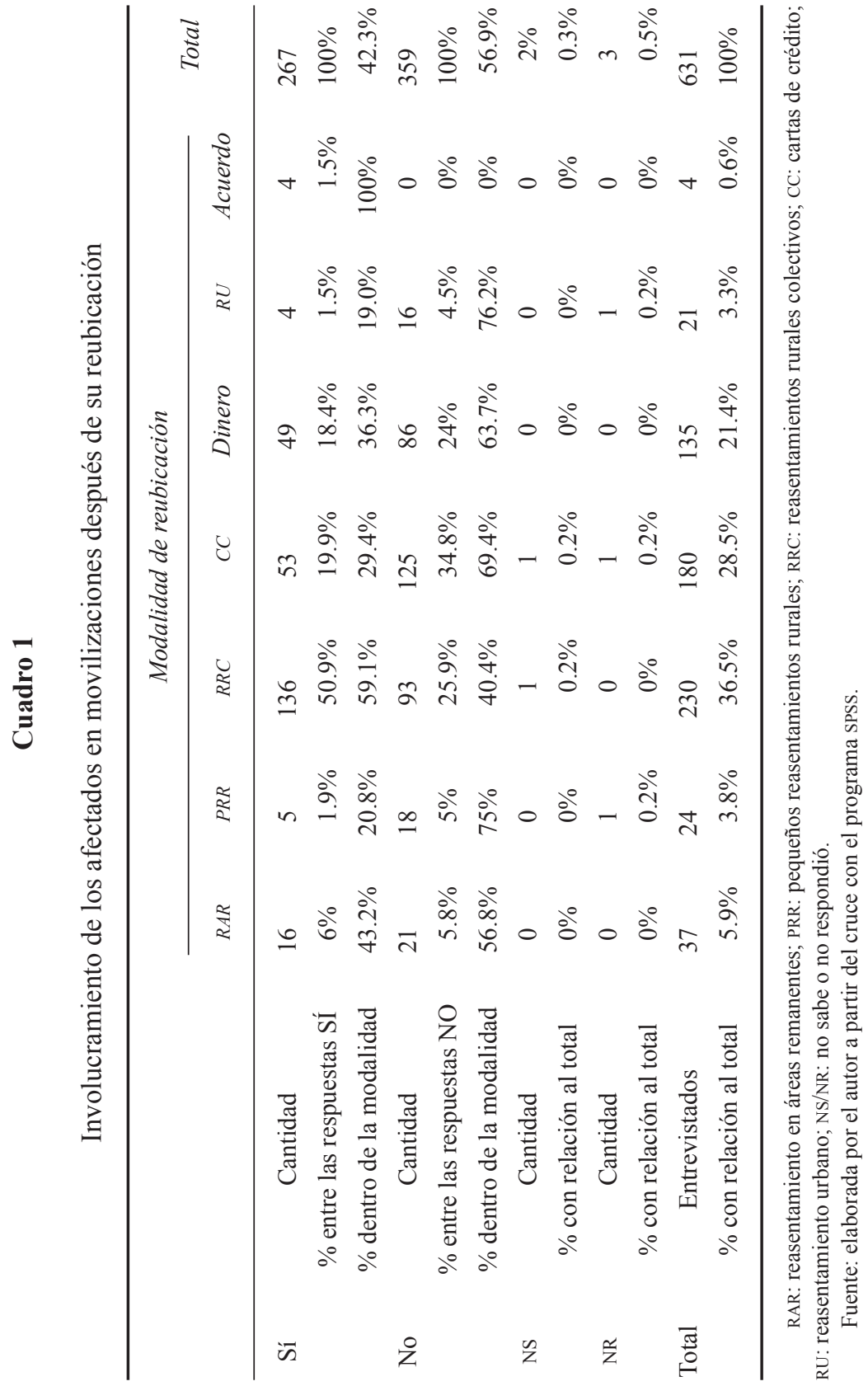


de datos, en tanto que el segundo permite un análisis causal más aproximado (Lieberman, 2005: 440). Para alcanzar las motivaciones que ayuden a comprender en qué medida esto se refleja en la "multiterritorializacion" del conflicto y cuál sería la influencia del MAB en el proceso a partir de la idealización de los RRC, nos dirigimos a las entrevistas a profundidad.

A partir de un cuestionario semiestructurado, los entrevistados manifestaron los motivos para participar o no en movilizaciones referentes a otros proyectos en el periodo posterior a su reubicación. Obtuvimos respuestas variadas y optamos por agruparlas según las categorías de sentido. Para ello formulamos el cuadro 2 de las motivaciones para participar en movilizaciones sociales contra las hidroeléctricas.

Para la elaboración de este cuadro organizamos las respuestas en grupos, en el sentido de reproducir las motivaciones más frecuentes. Además de no ser el objetivo de esta metodología, la búsqueda por la precisión estadística en las respuestas cualitativas queda comprometida por la ambigüedad de algunas respuestas. Por ejemplo, una respuesta como "ayudar a un compadre", podría ser clasificada según un sentido de solidaridad, pero también podría ser retribución o hasta interés propio. Así, optamos tan sólo por enlistar las motivaciones de mayor a menor frecuencia, de forma que entre las respuestas de "SÍ", que participaron en manifestaciones después de la reubicación, fueron más frecuentes las motivaciones que clasificamos como de "solidaridad humana" (40\%), "alineación con el MAB" (20\%), "intereses específicos" (20\%) y "retribución" (10\%). Entre las respuestas de "NO", o sea, de los que no habían participado en manifestaciones después de la reubicación, la respuesta más frecuente deriva del "trabajo en la propiedad" (40\%), seguida de "acomodo" (30\%), "individualismo" (15\%) y "alineación con los responsables del proyecto" (5\%). Después obtuvimos respuestas variadas, inconsistentes o que podrían ser clasificadas en sentidos diferentes. Según ya se dijo, para no establecer como prioridad en este cuadro la precisión estadística, sino más bien hacer una distribución mínima de las motivaciones, clasificamos estas respuestas bajo otro gran grupo ("Otros") que no interfiere ni pone en duda las conclusiones a partir de las respuestas más precisas.

Aquí nuevamente las explicaciones de Olson se hacen pertinentes. Al presentar una "taxonomía de los grupos", el autor distingue tres categorías explicativas para la acción colectiva. Olson llama "privilegiados" a aquellos grupos que entienden que el beneficio colectivo será alcanzado de manera independiente de la organización grupal. Éstos podrán proveer o no la acción colectiva por tener condiciones de lidiar solos con el gravamen a fin de alcanzar beneficios. Los "intermediarios" serían aquellos grupos que entienden que el beneficio colectivo solamente puede ser alcanzado por la 


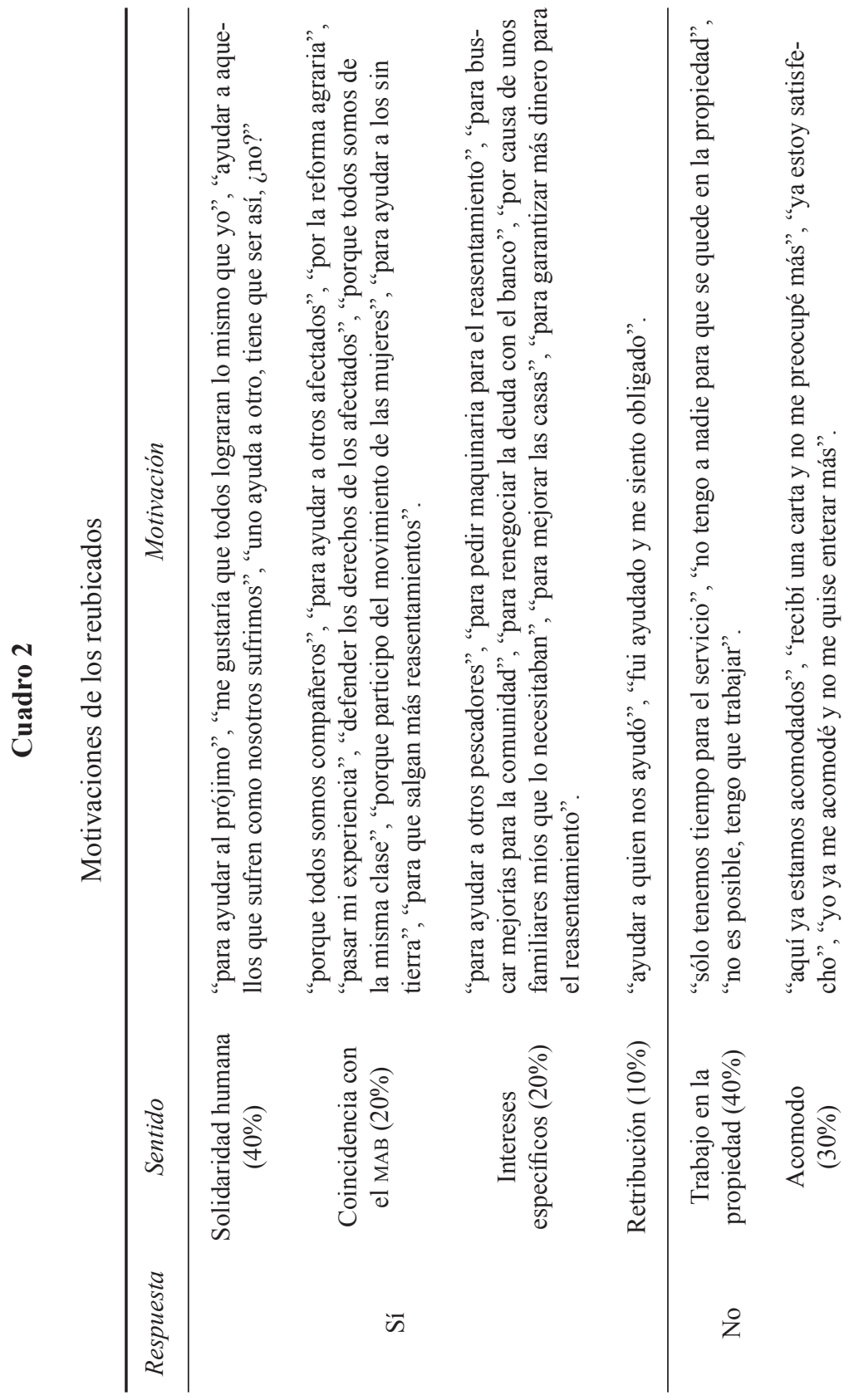




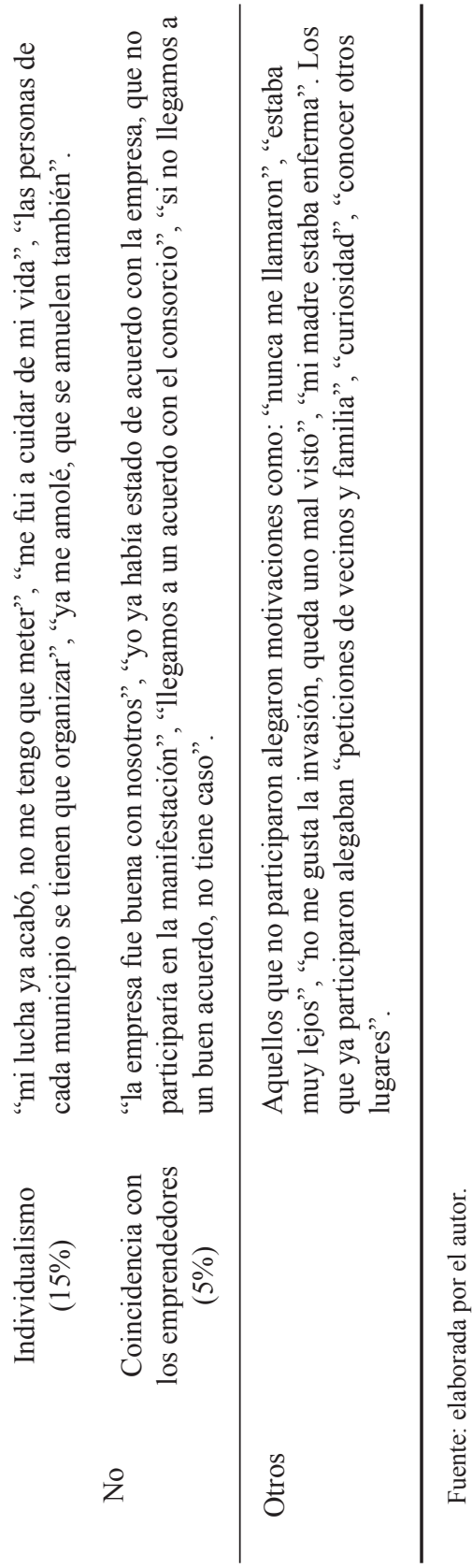


organización grupal. Ya los llamados "latentes" pueden o no movilizarse dependiendo de un "incentivo selectivo", algo de lo que, si ellos no participaron de la movilización, quedaron excluidos del beneficio, mientras que si éstos se movilizan asumen la forma de "grupo latente movilizado" (Olson, 2015: 62-63).

Al trasladar las ideas de Olson a nuestras investigaciones empíricas, notamos que los afectados reasentados corresponden a grupos de naturaleza "intermediadora" que militaron alineados con el MAB y que buscaron el reasentamiento como opción colectiva. Ya entre los asentados por cartas de crédito identificamos grupos "privilegiados" o "latentes" que negociaron de forma individualizada.

$\mathrm{Al}$ avanzar en la idea de tratar de comprender las opciones de los afectados mediante categorizaciones, Tilly (1977) presenta cuatro categorías a partir de la disposición de movilizar recursos según el valor que atribuye a determinado bien que estaría en juego, y además al cálculo de ventajas y desventajas involucradas en la disputa. En esta perspectiva, los llamados "zealots" (apasionados) estarían dispuestos a gastar abundantes recursos en nombre de un beneficio al que atribuyen alto valor; los "misers" (avaros) creen que la movilización colectiva no compensará las pérdidas que podrán sufrir sus recursos actuales; los "run of the mill" (contenidos) tienden a gastar el mínimo de recursos a cambio de los beneficios que también valoran de forma contenida; y los "opportunists" (oportunistas) buscan obtener el máximo de beneficios independientemente de la movilización de recursos de que disponen (Tilly, 1977, 3: 55-56).

Si hiciéramos una aproximación entre las categorizaciones de los autores citados veremos que los "run of the mill" corresponden a los "privilegiados", los "zealots" corresponden a los "intermediarios", mientras que los "misers" y "opportunists" corresponden a los "latentes". De esta manera veremos que los afectados que no optaron por la acción colectiva y lo hicieron por cartas de crédito corresponden a las categorías de "privilegiados" o "run of the mill"; es decir, no se movilizaron colectivamente cuando ocurrió la llegada de la hidroeléctrica, negociaron de manera individual y tienden a no participar en las acciones colectivas posteriores. Asimismo, los afectados que se orientaron a la acción colectiva cuando llegó la hidroeléctrica y fueron reasentados colectivamente, corresponden a los "zealots" o "intermediarios" y tienden a participar en movilizaciones futuras. En cuanto a los "misers" y los "opportunists", su "latencia" continúa.

Este es el esquema general de las motivaciones para la acción colectiva, aunque no debemos descuidar la naturaleza transitoria de la condición de afectado (Rocha, 2010). Aunque inicialmente determinado grupo se haya 
movilizado frente a la llegada de la hidroeléctrica, después de ser reasentado, su nueva condición de trabajo en la nueva propiedad y su acomodo hacen repensar la iniciativa de la movilización. En lo relativo a los asentados por carta de crédito, la indisposición anterior se mostró persistente y aun agravada por la dificultad para reunirse en virtud de haberse acomodado en lugares distantes del origen y de otros afectados.

Una vez respondida la cuestión acerca de las motivaciones de los afectados para participar o no en las movilizaciones, juzgamos que la "solidaridad humana" es el principal factor para la participación, independientemente de la modalidad de reubicación. Si juntamos las dos preguntas/respuestas, llegamos a la afirmación de que la mayoría de los afectados reubicados que participan en las movilizaciones es originario de RRC, modalidad propiciada por el MAB. Sin embargo, según los afectados mismos, la principal motivación para seguir en la lucha aun después de la reubicación es la solidaridad con aquellos que "sufrirán" el mismo proceso que otros sufrieron antes. De los argumentos presentados hasta aquí, en especial en esta sección, tratemos de vislumbrar los reasentamientos en el contexto del empoderamiento del MAB.

Actualmente, el MAB se encuentra insertado en una red de movimientos sociales articulados en torno a la Vía Campesina. ${ }^{5}$ En Brasil el movimiento tiene una dirección nacional con sede en São Paulo, desde donde busca articular las acciones en los diferentes lugares. El MAB presenta una estructura que se encuadra en una tendencia mundial actual de "una combinación de pequeños liderazgos profesionales, un apoyo de masa amplio pero principalmente pasivo y redes impersonales de estructuras conectoras" (Tarrow, 2009: 171). Esta estructura funciona bien con la ayuda de redes tecnológicas de comunicación que agilizan las articulaciones en diferentes partes del mundo. Este avance en la escala de actuación tiene un punto sensible, lo que con

${ }^{5}$ Nota: la Vía Campesina es un movimiento internacional que coordina aproximadamente a 150 organizaciones campesinas de pequeños y medianos productores, mujeres de áreas rurales, comunidades indígenas, personas sin tierra, jóvenes rurales y trabajadores agrícolas migrantes en los cinco continentes. Se originó en abril de 1992, y reunió a líderes campesinos de América Central, del Norte y de Europa, en el Congreso de la Unión Nacional de Agricultores y Trabajadores Pecuarios (UNAG), en Managua (Nicaragua). En mayo de 1993, la primera Conferencia de la Vía Campesina en Mons (Bélgica) estableció su organización global y definió orientaciones estructurales y estratégicas. El principal objetivo de esta organización es desarrollar la solidaridad y la unidad entre las organizaciones, promover las relaciones económicas de igualdad y justicia social, la preservación de la tierra, la soberanía alimentaria, la producción agrícola sustentable y la igualdad con base en la producción a pequeña y media escalas. En Brasil, además del MAB, integran la Vía Campesina: el Movimiento de los Trabajadores Sin Tierra (MST), Movimiento de Mujeres Campesinas (MMC), Movimiento de los Pequeños Agricultores (MPA) y Pastoral de la Juventud Rural (PJR). 
respecto al MAB es todavía más crucial. Dado que el movimiento adquirió la capacidad de cubrir diferentes lugares donde los conflictos surgen a partir de la instalación de las hidroeléctricas, el desafío es cómo mantener "núcleos permanentes de activistas en la base" (Tarrow, 2009: 172). Al centrarse en los reasentamientos, la cuestión que nos guía como resultado del trabajo es si el RRC puede ejercer esta función de movilización permanente o, en la perspectiva de la "malla de análisis", constituirse como un punto de empoderamiento del MAB en el enfrentamiento con los que proponen los proyectos de las hidroeléctricas.

Considerando tan sólo las mayores hidroeléctricas de la cuenca y sus respectivas reubicaciones poblacionales, tenemos una malla de análisis (figura 1) donde podemos ilustrar la "multiterritorialización" del conflicto. En esta perspectiva, podemos observar que, aunque el RRC todavía es el principal núcleo de movilización posterior a la reubicación, la mayor motivación de estos afectados para participar en nuevas manifestaciones se da principalmente a consecuencia de la solidaridad humana, y no por acción de una formación pedagógica desarrollada por el MAB. Sin menospreciar el trabajo pedagógico desarrollado por el movimiento social, la no participación en manifestaciones postreubicación se da principalmente por el "acomodo" y por el hecho de que los agricultores no "pueden" o "no quieren" apartarse de las nuevas propiedades para participar en esas manifestaciones. La evaluación parece ser la de que los costos de las movilizaciones están más allá de los beneficios, aun cuando estas propiedades hayan sido conquistadas a través de la movilización organizada por el MAB cuando se realizó la instalación de las hidroeléctricas.

Esta confluencia de factores apunta hacia el hecho de que el proyecto neoliberal tiende a fortalecer su "multiterritorialización" en cada nueva hidroeléctrica instalada, ya sea a través de la repetición de accionistas, ya sea por la interacción con las poblaciones locales remanentes. Por otro lado, el proyecto democrático participativo tiene en la "multiterritorialización" su gran desafío, ya que las cartas de crédito, con crecimiento de manera inversamente proporcional a los reasentamientos en cada nueva hidroeléctrica (Rocha, 2013), tienden a dispersar a los afectados y a dificultar la movilización social. Aunque los RRC sean todavía los lugares de mayor ocurrencia de manifestaciones postreubicación, según los resultados de nuestra investigación, el hecho de que estos afectados no hubieran presentado como principal motivación la "alineación con el MAB", hace recomendable una revisión sobre el trabajo de movilización del MAB.

Finalmente, nuestro trabajo intentó demostrar que la sucesión de las hidroeléctricas tiende a consolidar los ideales que están en armonía con el pro- 
yecto neoliberal a partir de la primacía del mercado y del desarrollismo. Por otro lado, los reasentamientos, puntos privilegiados para la actuación del $\mathrm{MAB}$, no presentan la misma influencia en el sentido de la participación de las comunidades locales en dicho proceso. Mas allá del carácter conclusivo, parcial, nuestra construcción abre precedentes hacia el análisis de la evolución de los movimientos sociales, en especial del MAB, así como de la actuación de las empresas públicas y privadas que componen el sector eléctrico brasileño.

Recibido: diciembre de 2014

Revisado: septiembre de 2015

Correspondencia: Universidade Federal da Fronteira Sul/Rodovia SC 459/Km 2/Área rural/Chapecó-SC/correo electrónico: humberto.rocha@uffs.edu.br

\section{Bibliografía}

ANEEL/BIG (Banco de Informações de Geração) (2015), en URL http://www.aneel. gov.br/aplicacoes/capacidadebrasil/capacidadebrasil.cfm, fecha de consulta septiembre de 2015.

Art, Henry W. et al. (1998), Dicionário de ecologia e ciências ambientais, São Paulo, Melhoramentos.

Bartolome, Leopoldo José (2000), "Esquema de reassentamento populacional como processos sociais: questões conceituais e metodológicas", en Walter Arensberg, Barragens, desenvolvimento e meio ambiente, São Paulo, s.n., pp. 163-167.

Bergamasco, Sônia Maria y Luiz Antônio Cabello Norder (1996), O que são reassentamentos rurais, São Paulo, Brasiliense.

Brasil, República Federativa de (1995), Lei n 9.074, de 7 de julho "Estabelece normas para outorga e prorrogações das concessões e permissões de serviços públicos e dá outras providências".

Castells, Manuel (2003), A sociedade em rede, vol. 1, A era da informação: economia, sociedade e cultura, séptima edición, São Paulo, Paz e Terra.

CMEB (Centro da Memória da Eletricidade no Brasil) (1988), Panorama do setor de energia elétrica no Brasil, Rio de Janeiro, Memória da Eletricidade.

Dagnino, Evelina, Alberto J. Olvera y Aldo Panfichi (orgs.) (2006), "Para uma outra leitura da disputa pela construção democrática na América Latina", en $A$ disputa pela construção democrática na America Latina, São Paulo y Campinas, Paz e Terra y UNICAMP.

Fernandes, Bernardo Mançano (1999), MST: Movimento dos trabalhadores rurais sem terra: formação e territorialização em São Paulo, segunda edición, São Paulo, Hucitec. 
Gonçalves Júnior, Dorival (2007), Reformas na indústria elétrica brasileira: a disputa pelas fontes e o controle dos excedentes, São Paulo, Programa Inter unidades de Pós-Graduação em Energia, Universidade de São Paulo, tesis de doctorado.

Haesbaert, Rogério (2005), "Da Desterritorialização à Multiterritorialidade", en Anais do XEncontro de Geógrafos da América Latina, São Paulo, X Encontro de Geógrafos da América Latina, pp. 6774-6792.

Ianni, Octavio (1997), A sociedade global, quinta edición, Rio de Janeiro, Civilização Brasileira.

Lieberman, Evans S. (2005), "Nested Analysis as a Mixed-Method Strategy for Comparative Research”, American Political Science Review, vol. 99, núm. 3, agosto, pp. 435-452.

Lima, José Luiz (1995), "Formação e desenvolvimento do setor de energia elétrica no Brasil republicano até a década de 1930", Centro da Memória da Electricidade no Brasil, ciclo de palestras: a Eletrobrás e a história do setor de energia elétrica no Brasil, Rio de Janeiro, Centro da Memória da Eletricidade no Brasil, pp. 9-36.

Lima, José Luiz, Arnaldo Rodrigues Barbalho y José Marcondes Brito de Carvalho (1995), "A trajetória do setor de energia elétrica na década de 1970", Centro da Memória da Electricidade no Brasil, ciclo de palestras: a Eletrobrás e a história do setor de energia elétrica no Brasil, Rio de Janeiro, Centro da Memória da Eletricidade no Brasil, pp. 163-219.

Lima, José Luiz, João Camilo Penna e Izaltino Camozzato (1995), “A trajetória do setor de energia elétrica na década de 1980", Centro da Memória da Electricidade no Brasil, ciclo de palestras: a Eletrobrás e a história do setor de energia elétrica no Brasil, Rio de Janeiro, Centro da Memória da Eletricidade no Brasil, pp. 221-262.

Lima, José Luiz, Lucas Lopes y John R. Cotrim (1995), “A intervenção direta do Estado e os novos padrões de desenvolvimento do setor de energia elétrica nas décadas de 1940 e 1950", Centro da Memória da Electricidade no Brasil, ciclo de palestras: a Eletrobrás e a história do setor de energia elétrica no Brasil, Rio de Janeiro, Centro da Memória da Eletricidade no Brasil, pp. 37-85.

Locatelli, Carlos (2014), Comunicação e barragens: o poder da comunicação das organizações e da mídia na implantação de hidrelétricas, Florianópolis, Insular.

Loera, Nashieli Rangel (2006), A espiral das ocupações de terra, São Paulo, Polis y Campinas, CERES/IFCH-UNICAMP.

Mielnik, O. y C. C. Neves (1988), "Características da estrutura de produção de energia hidrelétrica no Brasil”, en Luiz Pinguelli Rosa, Lygia Sigaud y Otavio Mielnik, Impactos de grandes projetos hidrelétricos e nucleares: aspectos econômicos e tecnológicos, sociais e ambientais, Rio de Janeiro y São Paulo, AIE/COPPE, Marco Zero y cNPq.

Moraes, Maria Stela Marcondes de (1994), "Reassentamentos de atingidos pelas barragens do rio Uruguai”, en Leonilde Medeiros et al. (orgs.), Assentamentos rurais: uma visão multidisciplinar, São Paulo, UNESP, pp. 157-175. 
Nicolas, Daniel Hiernaux (1996), “Tempo, espaço e apropriação social do território: rumo à fragmentação na mundialização?”, en Milton Santos, Maria Laura Silveira y Maria Adelia A. de Souza (coords.), Território: globalização e fragmentação, tercera edición, São Paulo, Hucitec.

Olson, Mancur (1999), A lógica da ação coletiva, São Paulo, Edusp.

Paim, Elisangela Soldatelli y Lúcia Schild Ortiz (coords.) (2006), Hidrelétricas na bacia do rio Uruguai: guia para ongs e movimentos sociais, Porto Alegre, NAT/Brasil.

Piran, Nédio (2001), Agricultura familiar: lutas e perspectivas no Alto Uruguai, Erechim, FAPES.

Poli, Odilon Luiz (1999), "Oeste catarinense: modernização, êxodo e movimentos sociais no campo", en Leituras em movimentos sociais, Chapecó, Grifos, pp. 63-163.

Poulantzas, Nicos (1981), O estado, o poder, o socialismo, Rio de Janeiro, Graal.

Prado Júnior, Caio (2004), História econômica do Brasil, primera edición, São Paulo, Brasiliense.

Raffestin, Claude (1993), Por uma geografia do poder, São Paulo, Ática.

Ribeiro, Gustavo Lins (1991), Empresas transnacionais: um grande projeto por dentro, São Paulo, Marco Zero y ANPOCS.

Rocha, Humberto José da (2014), “A criminalização dos movimentos sociais ante a instalação de uma hidrelétrica no Rio Uruguai (Brasil): uma discussão entre o legal e o legítimo", Idéias. Revista do Instituto de Filosofia e Ciências Humanas da UNICAMP, vol. 5, pp. 191-214.

Rocha, Humberto José da (2013), Relações de poder na instalação de hidrelétricas, Passo Fundo-Rs, Ediupf.

Rocha, Humberto José da (2012a), "Integração desintegradora: a trajetória de projetos hidrelétricos desde a IIRSA até as comunidades locais", Mural Internacional, vol. 3, pp. 30-36.

Rocha, Humberto José da (2012b), “As modalidades de remanejamento”, en Marcelo Baquero y Hemerson Luiz Pase, Estado, democracia e hidreletricidade no Brasil, Pelotas, Editora Universitária/UfPel, pp. 113-134.

Rocha, Humberto José da (2010), “A condição de atingido por barragem”, en Anais do I Seminário Internacional e III Seminário Nacional Movimentos Sociais, Participação e Democracia, Florianópolis-SC, pp. 386-400.

Rocha, Humberto José da (2009), "Carta aos atingidos: as negociações na bacia do rio Uruguai", en Anais do I Seminário Nacional Sociologia \& Politica: "Sociedade e Politica em Tempos de Incerteza”, Curitiba-PR, UFPR.

Rothman, Franklin Daniel (1996), "A emergência do movimento dos atingidos pelas barragens da bacia do rio Uruguai (1979-1983)", en Zander Navarro (org.), Política, protesto e cidadania no campo: as lutas sociais dos colonos e trabalhadores rurais no Rio Grande do Sul, Porto Alegre, Editora da Universidade/ UFRGS, pp. 106-136.

Tarrow, Sidney (2009), O poder em movimento: movimentos sociais e confrontos politicos, Petrópolis, Vozes. 
Tilly, Charles (1977), From Mobilization to Revolution, Reading, Addison-Wesley. Ventura, Zuenir (1988), 1968: o Ano que Não Terminou, Rio de Janeiro, Nova Fronteira.

Verdum, Ricardo (2007), "Obras de infraestrutura no contexto da integração SulAmericana", en (autor) (org.), Integração, usinas hidroelétricas e impactos socioambientais, Brasília, INESC, pp. 13-40.

Zhouri, Andréa y Raquel Oliveira (2010), "Quando o lugar resiste ao espaço: colonialidade, modernidade e processos de reterritorialização", en Andréa Zhouri y Klemens Laschefski, Desenvolvimento e conflitos ambientais, Belo Horizonte, Editora UFMG, pp. 439-462.

\section{Acerca del autor}

Humberto José da Rocha es doctor en ciencias sociales por la Universidad Estatal de Campinas. Actualmente es profesor adjunto de la carrera de Ciencias Sociales en la Universidade Federal da Fronteira Sul (UFFS). Sus áreas de interés son sociología, ambiente y obras de gran escala. De sus publicaciones citamos "O controle do espaço-tempo nos processos de instalação de hidrelétricas", Tempo Social, vol. 26, 2014, pp. 259-280; y “A criminalização dos movimentos sociais ante a instalação de uma hidrelétrica no Rio Uruguai (Brasil): uma discussão entre o legal e o legítimo", Idéias, vol. 5, 2014, pp. 191-214. 